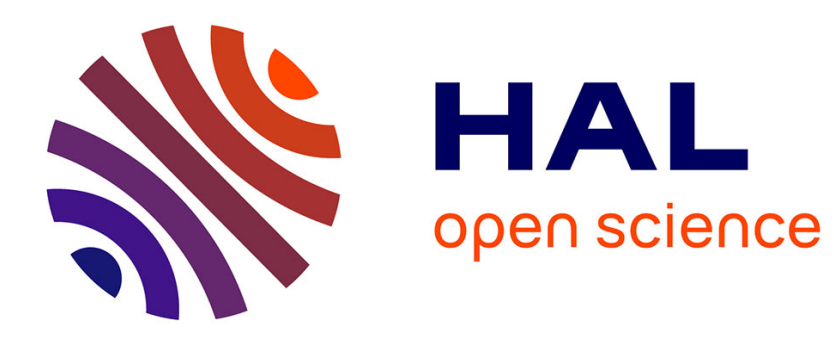

\title{
The Flow Stress Anomaly of L12 Alloys: Mechanical Properties
}

\author{
P. Veyssière
}

\section{To cite this version:}

P. Veyssière. The Flow Stress Anomaly of L12 Alloys: Mechanical Properties. Journal de Physique IV Proceedings, 1996, 06 (C2), pp.C2-185-C2-188. 10.1051/jp4:1996226 . jpa-00254204

\section{HAL Id: jpa-00254204 https://hal.science/jpa-00254204}

Submitted on 1 Jan 1996

HAL is a multi-disciplinary open access archive for the deposit and dissemination of scientific research documents, whether they are published or not. The documents may come from teaching and research institutions in France or abroad, or from public or private research centers.
L'archive ouverte pluridisciplinaire HAL, est destinée au dépôt et à la diffusion de documents scientifiques de niveau recherche, publiés ou non, émanant des établissements d'enseignement et de recherche français ou étrangers, des laboratoires publics ou privés. 


\title{
The Flow Stress Anomaly of L12 Alloys: Mechanical Properties
}

P. Veyssière

LEM(1), CNRS-ONERA, BP 72, 92322 Châtillon Cedex

\begin{abstract}
This contribution offers a brief account of the current knowledge of the mechanichal properties of $\mathrm{Ll}_{2}$ alloys deformed in the domain of temperature where their so-called flow stress anomaly takes place. Emphasis is put on the features which, on a macroscopic scale, may help identify properties of the rate-controlling mechanism(s). The paper is aimed at emphasizing that the flow stress anomaly is actually accompanied by a variety of atypical mechanical behaviours, of which none can be a priori suspected of being of minor importance in the design of a physically sound model.
\end{abstract}

\section{INTRODUCTION}

There is a nearly fourty years old tradition of mechanical tests on $\mathrm{Ll}_{2}$ alloys, essentially dealing with the increase in flow stress with temperature, knwon as the flow stress anomaly of $\mathrm{L}_{2}$ alloys.

In addition to characterizing the role of the many parameters such as compositon, orientation, deformation mode, etc... that effect the mechanical response of this category of alloys, a great deal of experiments had been designed in order to identify the mechanism(s) from which the spectacular increase of flow stress with temperature originates. After all these years of efforts from groups all over the world-efforts that include the particularly intensive research activity that took place during the early eighties where there has been a hope that $\mathrm{Ni}_{3} \mathrm{Al}$ would eventually "fly"-, the situation is now that of a well characterized system while still relatively poorly understood phenomenon. Reviewing the arguments on which such a pessimistic statement is founded is beyond the scope of this contribution which is aimed at concentrating on mechanical properties only. The reader should however find in the contributions to this colloquium of Caillard on the one hand and of Louchet on the other hand, material that will help him or her appreciate the wide gap that still separates models from nature.

The present contribution does not intend to offer another review on a topic that has already been covered a number of times over the last decade or so and this is why it will consist of a summary of experimental facts felt by the author to be essential in the understanding of this intriguing and fascinating mechanical property. In addition, the following is aimed at providing the reader with selected basic references to original works as well as to review papers where he or she may in turn collect most of the experimental and bibliographic information relevant to this subject. In particular, comprehensive information on this still rapidly evolving field can be taken from the following review papers [1-6].

While examples of a positive temperature dependence of the flow stress (TDFS) are scarce in simple metals and in disordered alloys, this property is encountered in almost every ordered structure investigated so far [7]. It sometimes corresponds to the exception of a particular alloy deformed under a specific slip system. In other cases the positive TDFS is a feature common to a large number of isostructural alloys-though not all of them-such as the family of $\mathrm{L} 1_{2}$ alloys. From a comparison between the many available cases, it is now accepted that there are certainly several categories of positive temperature dependencies of the flow stress, or stated differently, that the origin of positive TDFS should not be ascribed to an universal (locking-) dislocation process. We now focus on those $\mathrm{L}_{2}$ alloys that exhibit a positive TDFS.

(1) Unité Mixte de Recherche UMR 104 


\section{GENERALITIES ON THE MECHANICAL PROPERTIES OF L1 2 ALLOYS}

That the flow stress of some $\mathrm{L}_{2}$ alloys increases with temperature was reported for the first time in 1952 by Lowrie in $\mathrm{Ni}_{3} \mathrm{Si}$ [6]. It is only in the early 70's that the stage was clearly set after the contributions of Westbrook [9], Copley and Kear [10] and the remarkably perspicacious work of Thornton et al [11]. The situation was complemented a few years later by the discovery of the spectacular though complex orientation dependence of the flow stress (for a review, see [1-2], the critical discussion in [6] and the comprehensive experimental work of Heredia[12]). It is only in the last decade or so that the importance of creep properties, of the strain-rate sensitivities and of the flow stress reversibility with temperature was made clear. On the other hand, it is interesting to note that almost every feature that is instrumental in the interpretation of the flow stress anomaly was present in the micrographs published in the early TEM papers [10-11]. Nevertheless, it took another 20 years - with the most significant progress achieved in the last decade-before these features could make enough sense to allow for a reasonable embryo of scenario for the dynamical organization of the microstructure that could be related to the general macroscopic behaviour in a physically sound manner.

Worth of consideration is the fact that in $\mathrm{Ll}_{2}$ alloys the magnitude of the anomaly as well as the peak temperature are dramatically composition dependent [2] for reasons that remain largely obscure.

\section{THE FLOW STRESS ANOMALY AND ACCOMPANYING PROPERTIES}

With regard to mechanical properties, the positive TDFS can be characterized as follows:

0 - in the domain of flow stress anomaly, slip occurs on the octahedral $<110>\{111\}$ slip system, regardless load orientation, with some propensity towards cross-slip on another octahedral plane and on the cube plane at low and high temperatures, respectively. Actually, cube cross-slip appears to take over octahedral cross-slip in the early stages of the increase of flow stress with temperature while cube slip - be it of cross-slip or primary nature takes a gradually increasing role as the peak temperature is approached and becomes overwhelming above the peak (some precaution should be taken concerning the near-[001] region of the load orientation). The change in cross-slip system is actually consistent with the widely accepted fact that cube slip is highly thermally-activated while there is hardly no lattice friction on the octahedral plane.

1 - of course, the critical resolved shear stress (CRSS) measured at $0.2 \%$ of permanent strain increases with increasing temperature. In $\mathrm{Ni}_{3} \mathrm{Al}$-based alloys, which is the most documented family within the $\mathrm{Ll}_{2}$ structure, one is dealing with CRSSs ranging between 50 and $600 \mathrm{MPa}$ within a temperature domain located between $300 \mathrm{~K}$ and $1100 \mathrm{~K}[2,12]$.

2 - the Schmid law is violated: the CRSS measured in tension differs from that in compression by some stress increment whose amplitude and sign are themselves orientation-dependent. This property known as the tension-compression asymmetry has been regarded for a while as the only property of interest in addition to the positive TDFS from which resulted a period of stagnation in the understanding of the phenomenon.

3 - the CRSS is (very) little strain-rate sensitive: for a strain-rate jump by a factor of 20 , the stress increment amounts to 1 to $2 \%$ [11,13-14]. In view of the thermally activated nature of the anomaly in general and of cube cross-slip in particular (known to control to a large extent the locking of dislocations), this lack of strain-rate sensitivity is evidently a paradoxical signature of the positive TDFS. It is interesting to note that it had remained essentially ignored in all the models of the flow stress anomaly that have been produced until the late eighties.

4 - there is direct macroscopic evidence of a significant exhaustion rate as demonstrated by stress relaxation experiments [15], creep tests [16] and by the extensive microyielding regime under constant strain rate [17]. The behaviour under creep is to some extent rather atypical in that in the domain of positive TDFS the primary stage is followed by a stage exhaustion (the creep rate nearly cancels), which in 
fact is better regarded as an incubation stage since it it marks the transition between deformation under octahedral (primary) and cube slip (inverse). While the creep response is normal under cube slip-the creep rate increases with temperature-, it is atypical in the primary stage for the creep rate decreases as test temperature is increased. This contrasted behaviour between primary and inverse creep is actually fully consistent with the fact that cube slip is controlled by a significant lattice friction while the microstructure under octahedral slip becomes sooner or later nearly frozen-in as a result of the intrinsic locking of dislocations and/or of their mutual annihilation.

5 - a sample prestrained at a temperature $T_{1}$ higher than that of the second test $T_{2}$, softens significantly at $T_{2}$. This property is known as the so-called flow stress reversibility [11,16-18]. The larger the prestrain, the larger the stress increment between the re-strained sample and a virgin sample deformed at the second temperature. The property of stress reversibility is at variance from the usual behaviour of alloys which tend to retain under the form of an internal stress, a significant fraction of the stress attained at the end of the first test. It is then expected that the flow stress is less dependent upon properties of organization of the microstructure than on properties of individual dislocations (or else on short range interactions between these). In the same vein, the yield stress of a specimen prestrained at room temperature increases only slowly up to a temperature above which the yield stress of a virgin specimen is greater [19]. Above that temperature, the yield stress tends to increase as for a virgin crystal-for sufficiently high pre-stresses, the yield stress anomaly disappears completely. At variance from the prestrain at a higher temperature, some "internal stress" is then retained in the crystal, whose origin remains insufficiently discussed.

6 - the work-hardening (WH) rate is extremely large, up to $\mu / 10$ depending on sample composition and load orientation, and it shows a peak at a temperature lower than that of CRSS by 100 to $200 \mathrm{~K}$. The classical WH theories do not account for such levels of WH rate [20] and there is no clear idea as to the origin of such a dramatic and highly atypical effect. Again the work-hardening rate, whose dependencies upon temperature and load orientation are very reproducible from one alloy composition to the next, should be regarded as a signature of the flow stress anomaly.

7 - in complement to points 3 and 6 , the yield stress $\tau_{y}$ at small strains (of the order of $0.01 \%$ ) is strain rate independent and has the same anomalous temperature dependence as that of the $0.2 \%$ strained samples. The strain-rate sensitivity $\beta$ of the flow stress is associated with $\mathrm{WH}$ and $\beta$ is proportional to the WH increment $\left(\tau-\tau_{y}\right)$ obeying a Cottrell-Stokes law. The slope $\beta /\left(\tau-\tau_{y}\right)$ is about $1 \%$, nearly orientation independent, and decreases with temperature suggesting a change in the rate controlling mechanism [13$14,21]$.

8 - as stated earlier, the above mechanical properties are highly composition-dependent.

Some $\mathrm{Ll}_{2}$ alloys, such as $\mathrm{Co}_{3} \mathrm{Ti}$, may in addition show a negative TDFS at low temperature; others, such as $\mathrm{Pt}_{3} \mathrm{Al}$ and $\mathrm{Fe}_{3} \mathrm{Ge}$, just exhibit a negative and no positive TDFS [5-6].

\section{CONCLUSION}

The most significant macroscopic and microscopic properties related to the flow stress anomaly are now collected and most of them are well-documented though not always understood. It is clear that the flow stress anomaly should be better regarded as a collection of atypical mechanical properties. With regard to these, we are not expecting more than refinements from future experiments. Hence, whereas almost no pieces of the puzzle seem to be missing at present, the picture appears to make sense only by fragments. Clearly, some effort is still needed as to find out how all these fragments fit together.

\section{References}

[1] Pope D.P. and Ezz S.S. Int. Met. Reviews 29 (1984) 136-167.

[2] Suzuki T., Mishima Y. and Miura S., ISIJ International 29 (1989) 1-23.

[3] Khantha M. and Vitek V. "A theory of the unpinning and pinning mechanisms in $\mathrm{Ll}_{2}$ compounds in the anomalous regime", International Symposium on Structural Intermetallics, Champion USA sept. 1993, R. Darolia, J.J. Lewandowski, C.T. Liu, P.L. Martin, D.B. Miracle and M.V. Nathal Eds. (The 
Minerals, Metals and Materials Society, Warrendale, 1993), pp. 399-408.

[4] Hirsch P.B., Mater. Res. Soc. Proc. 288 (1993) 33-43.

[5] Sun Y.Q. MRS Bulletin, XX-7 (1996) 29-36.

[6] Veyssière P. and Saada G. 1996, Dislocation in Solids, F.R.N. Nabarro Ed. (North Holland, Amsterdam, 1996) in press.

[7] Veyssière P., Rev. Phys. Appl. 23 (1988) 431-443.

[8] Lowrie R., Trans. A.I.M.E. 194 (1952) 1093-1099.

[9] Westbrook J.H., Trans. A.I.M.E. 209 (1957) 898-912.

[10] Copley S.M. and Kear B.H., Trans. Met. Soc. A.I.M.E. 239 (1967) 977-984.

[11] Thornton P.H., Davies R.G. and Johnston T.L. Metall. Trans. 1 (1970) 207-218.

[12] Heredia H.F., Ph. D. Thesis (University of Pennsylvania, 1990).

[13] Ezz S.S., and Hirsch P.B., Phil. Mag. A 69 (1994) 105-127.

[14] Ezz S.S., and Hirsch P.B., Phil. Mag. A 72 (1995) 383-402.

[15] Spätig P., Ph. D. Thesis (University of Lausanne, 1995).

[16] Hemker K., Mills M.J. and Nix W.D., J Mater. Sci. 7 (1992) 2059-2069.

[17] Shi X., Saada G. and Veyssière P., Phil. Mag. A (1966) in press.

[18] Dimiduk D.M. and Parthsarathy T.A., Phil. Mag. Letters 71 (1995) 21-32.

[19] Ezz S.S, and Hirsch P.B., Mater. Res. Soc. Proc. 364 (1993) 719-724.

[20] Saada, G., P. Veyssière, "A theory of the unpinning and pinning mechanisms in $\mathrm{Ll}_{2}$ compounds in the anomalous regime", International Symposium on Structural Intermetallics, Champion USA sept. 1993, R. Darolia, J.J. Lewandowski, C.T. Liu, P.L. Martin, D.B. Miracle and M.V. Nathal Eds. (The Minerals, Metals and Materials Society, Warrendale, 1993), pp. 379-391.

[21] Ezz S.S. Sun Y.Q. and Hirsch P.B., Mater. Res. Soc. Proc. 364 (1993) 695-700. 